\title{
Skeletons in the Nuclear Cupboard
}

by our Washington Correspondent

The General Accounting Office (GAO), which recently embarrassed the $\mathrm{Re}$ publican Party by disclosing alleged violations of the law in connexion with campaign funding, has now also embarrassed the Atomic Energy Commission by publishing a critical report on the AEC's regulation of users of radioactive materials. Not only does the report document a number of alarming cases of public exposure to overdoses of radioactivity, but it also casts doubt on the commission's ability to prevent blatant violation of its own regulations. On the bright side, however, the report does suggest that the commission is beginning to take steps to put its house in order.

The GAO investigation was concerned with regulation of licences for use of radioactive compounds ranging from fuel processing and waste disposal to research and medical treatment. Some 16,300 such licences had been issued by the AEC up to June last year, and of these 8,200 were being regulated directly by the AEC, while the remaining 8,100 were regulated by the states under agreement with the AEC.

The regulations are supposedly designed to ensure that public exposure to radiation is kept within safe limits, whatever they are, but the GAO has found that this intention is not always fulfilled. The report says that in 5,616 inspections carried out by AEC staff between January 1968 and December 1971, there were no fewer than 1,932 violations of the regulations-ranging from insufficient warning of radioactivity areas and poor record keeping to blatant failure to report accidents and totally inadequate safety precautions. Although most of these violations were minor and, according to the GAO, were put right after a letter or an informal warning from the AEC, some were particularly serious and were not put right for a long time if at all. (The GAO euphemistically refers to such violators as "problem licensees".) Perhaps the most serious allegation in the GAO report is that the AEC took no stronger action against the majority of the problem licensees than to ask for an explanation of the violation and details of the steps the violator intends to take to prevent future violations. Moreover the GAO takes the AEC to task for not moving quickly enough after a violation had been discovered.

The GAO inspected ten problem licensees in detail and a short description of some of the violations is sufficient to show the seriousness of them. In one case, for example, a fuel processing company was inspected by the AEC 23 times up to August last year, and 18 of the inspections turned up one or more violations of the regulations. Nine inspections found radiation levels above the limits in and around the plant, including in an occupied apartment block next door, and there was also a history of overexposure of employees to radiation. But not until March 1971 did the AEC threaten the licensee with nonrenewal of his licence, after which, the GAO reports, steps were taken to correct the violations.

In another plant, excess radiation levels were found in a business firm next door and radioactive contamination was even found on public sidewalks around the plant. Eventually the licence was modified to include stronger controls, after which the plant suspended operations for some time. But soon after it started up again, there was an accident which resulted in plutonium contamination of several areas of the plant, two of its employees and the surrounding area; the AEC was then forced to deny the licensee's request for renewal of his licence. The GAO also examined two cases involving medical facilities in which patients were given millicurie doses of radioactive compounds instead of microcurie doses, chiefly because of inadequate training and supervision of staff. Both resulted in the death of the patient. The AEC inspected one of these two medical facilities in April this year, and found six items of noncompliance with the regulations, but took no enforcement action

Some of the reasons the GAO cites for the AEC's poor record in enforcing its regulations are common enough-for example, there is a lack of staff, with only 31 inspectors and investigators to police some 8,200 licensees. But the accounting office also believes that the AEC's procedures are also partly to blame. For one thing, until September 1971, the agency lacked enforcement powers stronger than simply asking for explanations of violations but short of suspending or not renewing licences. Consequently, since licences were rarely revoked, the AEC did not have sufficient weapons at its disposal to force licensees to comply with the regulations. (Why the AEC did not simply shut down plants until they complied with the regu- lations is, however, open to question.) The agency can now impose civil penalties on violators, however.

The GAO also criticizes the AEC for not requiring licensees to give proper training and supervision in the administration of radioactive materials in medicine, but the agency is now taking steps to remedy this situation.

In defence of the AEC's enforcement record, however, L. Manning Muntzing, the Director of Regulation, pointed out in a letter to the GAO in March this year that the majority of the violations were cleared up after a letter from the AEC, and that the number of problem licensees is very small-the agency identified nineteen such cases between May and July last year. Nevertheless, he said that the AEC intends to use its new power to impose civil penalties to good effect. Muntzing also points out that the radiation levels set by the AEC are "much lower than levels which are likely to cause observable biological damage" and that "exposures in excess of the regulatory limits discussed in (the GAO report) should not be viewed as necessarily affecting the health of the exposed individual". Finally, Muntzing suggests that since there have only been twelve known cases of misadministration of radiopharmaceuticals, in spite of the fact that some eight million such administrations are performed each year, the safety record, compared with that for non-radiological drugs, "appears to be extremely favourable".

Nevertheless, the fact remains that one third of the AEC's inspections have turned up violations of regulations designed to protect public health. Unless the AEC acts promptly and decisively to remedy such violations, public confidence in the commission will be even further eroded.

\section{NITRITES \\ Nitrites in Trouble}

by our Washington Correspondent

THE American public each year consumes some 1,060 million pounds of food additives-about 5 pounds per person. Not surprisingly, there is growing public concern about the effects of these additives, and consumer groups have recently won a series of spectacular victories over the food manufacturing industry, not least of which was the ban on cyclamates in 1969 and the recent execution order on diethylstilboestrol. The Food and Drug 